\title{
DESIGN, FABRICATION AND TESTING OF HYDROCYCLONE SEPARATOR AS SEDIMENT SEPARATION SYSTEM
}

\author{
Bibek Aryal, Prithivi Gurung, Samman Singh Pradhan, Rakish \\ Shrestha \\ Department of Mechanical Engineering \\ School of Engineering, Kathmandu University \\ Kavre, Nepal \\ bbkar177@gmail.com \\ Aman Kapali \\ Turbine Testing Laboratory \\ Department of Mechanical Engineering \\ School of Engineering, Kathmandu University \\ Kavre, Nepal
}

\author{
Rabin Dhakal \\ Department of Mechanical Engineering \\ Texas Tech University \\ Lubbock, Texas \\ $\underline{\text { Rabin.Dhakal@ttu.edu }}$
}

\begin{abstract}
Hydrocyclone is a simple mechanical device, with no moving parts, where solid particles are separated from liquid with very little head loss. As its name describes, it uses a cyclone or tangential injection flow process enhancing the centrifugal forces and moving solids outwards. The dispersed particles, move downwards in a spiral path into an underflow chamber, while clean liquid move upwards to the center of the spiral, towards the top outlet. In this way, sand and other particles get separated from the water. Due to the various types of sediments in the water the mechanical parts of the turbine are damaged. Mainly sediments which are hard and also contains sharp edges causes the most damage to the turbine blade. Such problems due to sediments arise due to varying climate and terrain of Nepal. This problem of erosion of mechanical part due to sediments has become a global maintenance problem of hydropower plants. This is natural phenomena so it can neither be controlled nor completely stopped but it can be managed. So that we used this project as model for protecting turbine blades. The model is designed for the removal of sediments of size around 48 microns and larger sizes from sedimental water. The model is designed with combination of $16^{\circ}$ cone angles and $0.027,0.027$ and $0.010 \mathrm{~m}$ inlet, overflow, underflow cylinder diameters respectively. The hydrocyclone is fabricated with $1.6 \mathrm{~mm}$ thick mild steel sheet. The initial water sand mixture is compared with the resulting underflow and overflow.
\end{abstract}

Keywords-Hydrocyclone Separator, Sediments, cut size

\section{Introduction}

Originally in the later part of the 19th century hydrocyclone was used as a solid/liquid separator to remove sand from well water. Later on cyclone shape hydroelectric power plant is also introduced with name Gravitational Water Vortex Power Plant [1] [2] [3] [4].A typical hydrocyclone consists of a cylindrical section, a conical section, an underflow cylinder section and a sand collection basket. The separation is based on density difference between the liquid and the matter to be separated. The principle of centrifugal separation is used to remove or classify solid particles from a fluid, based on particle size, shape and density. Due to the various types of sediments in the water the mechanical parts of the turbine are damaged. Mainly sediments which are hard and contains sharp edges cause the most damage. According to research the most damage is caused in the turbine blade by these sediments. Such problems arise due to varying climate and terrain of Nepal. This problem of erosion of mechanical part due to sediments has become a global maintenance problem of hydropower plants. This is natural phenomena so it can neither be controlled nor completely stopped but it can be managed. [5] [6]

\section{Methodology}

In hydrocyclone unit must be installed vertically with sedimentation tank under the hydrocyclone. Conical shape accelerates the velocity of the water increasing centrifugal forces and maximizing separation. It's easy to operate and maintain with no moving parts or screens. There is no head loss build-up or clogging during separation. 
There are various design parameters of hydrocyclone which are as follows:

\section{Cone angle:}

For design purpose, $16^{\circ}$ cone angles were chosen [7] .The larger the hydro cyclone diameter, the coarser the separation. The included angle of the cone section is normally between $10^{\circ}$ and $20^{\circ}$.

\section{Cone section length:}

The length of cone depends upon the underflow cylinder diameter and cone angle. And for this project we made it $0.280 \mathrm{~m}$.

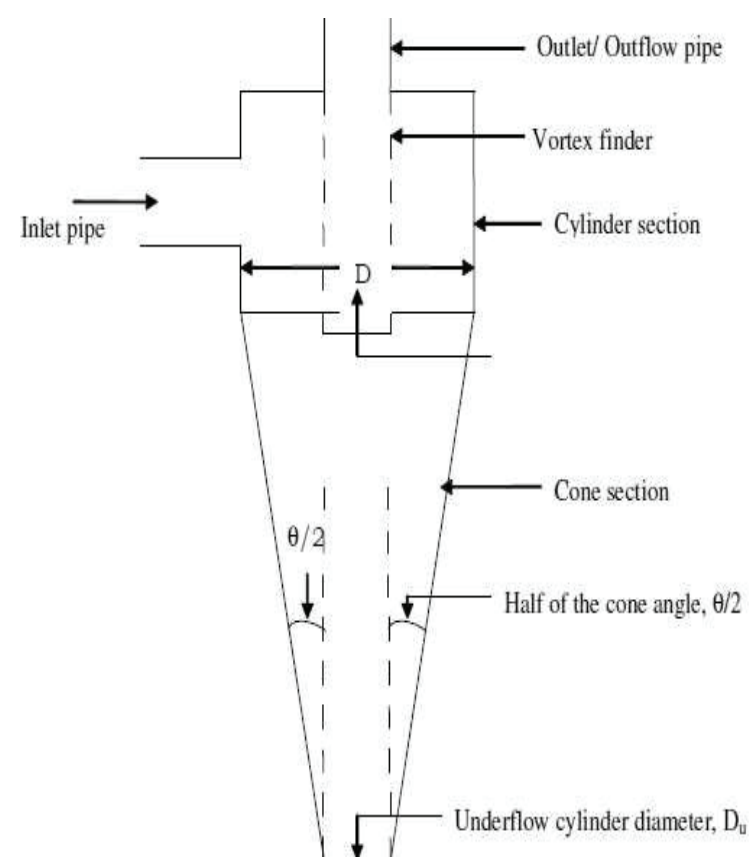

Fig. 1. Typical Hydrocyclone [6]

\section{Inlet and overflow section diameters:}

The inlet and overflow pipe diameter values were fixed at 0.027 and $0.027 \mathrm{~m}$, respectively for a flow rate of $3.6 \mathrm{~m} 3 / \mathrm{h}$. To increase the intake capacity of a hydrocyclone, its inlet diameter has to be increased.

\section{Cylinder section diameter:}

In the present study, all the six models including the control model had a diameter of $0.198 \mathrm{~m}$ (I.D.) which was 3.73 times the overflow pipe diameter. The diameter of cylinder section of the cyclone should be 2 times the overflow pipe diameter.

For this project cylinder diameter is $0.100 \mathrm{~m}$.

\section{Cylinder section length:}

Typically, hydrocyclone have a cylinder section length equal to or greater than the hydrocyclone diameter. The length of cylinder section should be 3 times the overflow pipe diameter. In the present study, the cylinder section length was chosen as 2.5 times the overflow pipe. For this project we made the length $0.070 \mathrm{~m}$.

\section{Vortex finder design:}

Vortex finder takes the clean water and delivers it to the outlet. If the length of vortex finder increases, it is likely to disturb the vortex and result in coarser separation of particles. So, the length of the vortex finder should be optimum and is found by a trial and error method. In this study, the length of the vortex finder was kept at $0.16 \mathrm{~m}$.

\section{Height of hydrocyclone:}

The height from the top of the outflow pipe to the end of the underflow cylinder section is referred to as total height of hydrocyclone. And for this project the total height of the hydrocyclone is $0.40 \mathrm{~m}$.

\section{Cut size:}

The cut size is defined as the diameter (d ) of a particle, which has a probability of $n \%$ to end up in the underflow section. The design probability (n) of trapping of particles in the collection basket was taken as $50 \%$. Particle separation is based on the density difference between the liquid and the matter to be separated. A higher density difference results in a finer separation. The hydrocyclone was designed by using the mathematical expression given by,

$$
\mathrm{d}_{p}=\sqrt{\frac{\mathrm{n} \times 0.01 \times 0.5\left(\mathrm{D}-\mathrm{D}_{0}\right) \times 18 \mathrm{\eta}}{\left(\rho_{s}-\rho_{l}\right) \lambda \mathrm{a}}}
$$

where,

$$
\begin{aligned}
& d_{p}=\text { Diameter of removed particle, } \mathrm{m} \\
& \mathrm{n}=\text { Probability of trapping of particles, } \% \\
& \mathrm{D}=\text { Diameter of cylindrical part, } \mathrm{m}
\end{aligned}
$$


$D_{0}=$ Diameter of overflow, $\mathrm{m}$

$\eta=$ Dynamic viscosity of water, pa-s

$\Omega_{s}=$ Density of solid, $\mathrm{kg} / \mathrm{m}^{3}$

$\rho_{l}=$ Density of liquid, $\mathrm{kg} / \mathrm{m}^{3}$

$\lambda=$ Residence time, $\mathrm{s}$

$\mathrm{a}=$ Acceleration, $\mathrm{m} / \mathrm{s}^{2}$

$\lambda=\frac{\mathrm{L}}{\frac{\mathrm{Q}}{\pi\left(\frac{\mathrm{D}^{2}-\mathrm{D}_{0}{ }^{2}}{4}\right)}}$

$\mathrm{L}=$ Length of cyclone from top inlet to end of cone, $\mathrm{m}$

$\mathrm{a}=\frac{\mathrm{U}_{i}{ }^{2}}{\mathrm{D} / 2}$

where, $\mathrm{U}_{i}=$ Initial velocity, $\mathrm{m} / \mathrm{s}$

$\mathrm{U}_{i}=\frac{\mathrm{Q}}{\mathrm{A}_{c}}$

Where, $\mathrm{Q}=$ Inlet flow rate, $\mathrm{m}^{3} / \mathrm{s}$

$\mathrm{A}_{c}=\frac{\pi}{4} \times D_{0}{ }^{2}=$ Cross-sectional area of inlet pipe, $\mathrm{m}^{2}[8]$.

\section{Fabrication and testing of hydrocyclone:}

The cylinder section and cone section of the hydrocyclone was fabricated by using M.S. (mild steel) sheet of $1.6 \mathrm{~mm}$ thickness. Commercially available $0.027 \mathrm{~m}$ diameter mild steel pipe was used to fabricate the inlet and outlet sections of the hydrocyclone.

\section{Experimental procedure:}

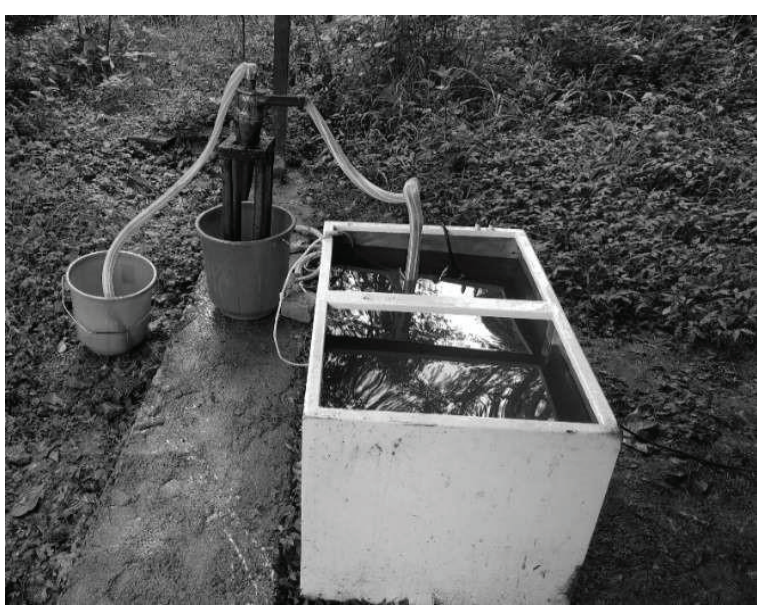

Fig. 2. Testing of hydrocyclone
The experimental setup for testing the hydrocyclone performance is illustrated in the Fig. 2.

The pump of $1.5 \mathrm{~L} / \mathrm{s}$ discharge rate was taken for the testing of the hydrocyclone. Experimentally, the discharge rate of the pump was found to be $1.35 \mathrm{~L} / \mathrm{s}$ by putting some specific known volume of water and noting the time at which the pump discharges that specific volume. Then, 100 gm sediment of size less than $250 \mu \mathrm{m}$ was added to the water of known volume. It was noted that the overflow discharge rate was $1 \mathrm{~L} / \mathrm{s}$. The clean water pressure drops in the model of hydrocyclone was recorded. The sample of $200 \mathrm{~mL}$ from each of the three outlets was collected and analyzed and the concentration was filtered using filter paper. The dry mass of the sediment was measured to calculate the efficiency of the cylone. These values were then compared with the particle size distribution of the sand sample that was fed into the system. The overall trapping efficiency of the hydrocyclone was calculated by using the following formula given by

$\mathrm{E}=\left[\frac{\mathrm{w}_{u}}{\mathrm{w}_{f}}\right] \times 100 \%$

where,

$\mathrm{E}=$ trapping efficiency of hydrocyclone, dimensionless

$\mathrm{W}_{u}=$ mass fraction in the feed flow, dimensionless

$\mathrm{W}_{f}=$ mass fraction in the underflow, dimensionless [8]

\section{RESULTS AND DISCUSSION}

The results obtained from the experiment on design, fabrication and testing of hydrocyclones are discussed in this section.

\section{Design of hydrocyclone:}

It was observed that the cone angle and the underflow cylinder diameter were the main variables for the design of the hydrocyclone. The model was designed to remove particles of size 48 microns and more. 
Here we take,

$$
\begin{aligned}
& \mathrm{n}=50 \% \\
& \mathrm{D}=0.10 \mathrm{~m} \\
& D_{0}=0.027 \mathrm{~m} \\
& \mathrm{\eta}=8.96 \times 10^{-4} \text { pa.s } \\
& \Omega_{s}=1680 \mathrm{~kg} / \mathrm{m}^{3} \\
& \Omega_{l}=1000 \mathrm{~kg} / \mathrm{m}^{3} \\
& \mathrm{~L}=0.40 \mathrm{~m} \\
& \mathrm{Q}=0.001 \mathrm{~m} / \mathrm{s} \\
& \mathrm{A}_{c}=\frac{\pi}{4} \times(0.027)^{2}=5.72 \times 10^{\wedge}-4 \mathrm{~m}^{2} \\
& \lambda=\frac{\frac{Q}{\pi\left(\frac{\mathrm{D}^{2}-\mathrm{Do}^{2}}{4}\right.}}{3(\mathrm{~s}} \\
& \mathrm{U}_{i}=\frac{Q}{\mathrm{~A}_{c}}=0.74 \mathrm{~m} / \mathrm{s} \\
& \mathrm{a}=\frac{\mathrm{U}_{i}^{2}}{\mathrm{D} / 2}=60.96 \mathrm{~m} / \mathrm{s}^{2}
\end{aligned}
$$

Now,

$$
\begin{aligned}
& \mathrm{d}_{p}=\sqrt{\frac{\mathrm{n} \times 0.01 \times 0.5\left(\mathrm{D}-\mathrm{D}_{0}\right) \times 18 \mathrm{\eta}}{\left(\rho_{s}-\rho_{l}\right) \lambda \mathrm{a}}} \\
& \mathrm{d}_{p}=\sqrt{\frac{\begin{array}{c}
50 \times 0.01 \times 0.5 \times(0.10-0.027) \times 18 \\
\times 8.96 \times 10^{-4}
\end{array}}{(1680-1000) \times 3 \times 60.96}} \\
& \mathrm{~d}_{p}=48.57 \times 10^{-6}=48 \mu \mathrm{m}
\end{aligned}
$$

Therefore, the diameter of removed particle for our hydro cyclone must be $48 \mu \mathrm{m}$.

Again, for efficiency of hydrocyclone

Total mixture $=8000 \mathrm{gm}+100 \mathrm{gm}=8100$

$$
\begin{gathered}
\mathrm{W}_{u}=\text { Mass fraction of underflow } \\
\mathrm{W}_{u}=\frac{\text { Mass of underflow }}{\text { Totalmixture }}=\frac{70 \mathrm{gm}}{8100 \mathrm{gm}} \\
\mathrm{W}_{f}=\text { Mass fraction of feed } \\
\mathrm{W}_{f}=\frac{\text { Mass of feed }}{\text { Total mixture }}=100 \mathrm{gm} / 8100 \mathrm{gm}
\end{gathered}
$$

$$
\mathrm{E}=\left[\frac{\mathrm{W}_{u}}{\mathrm{~W}_{f}}\right] \times 100 \%
$$

Where, $\mathrm{E}=$ Efficiency

$$
E=\left[\frac{70}{100}\right] \times 100 \%=70 \%
$$

According to the calculation, it is assumed that the hydrocylone separator should be able to separate particle size of more than 48 microns and it was planned to design the separator accordingly. After the fabrication, the testing is performed with the separator using the sand that was available of less than 250 microns and the efficiency is calculated by measuring certain volume of underflow, overflow and the feed rate and nearly $70 \%$ efficiency was found which shows that this design and the final result was somewhat similar as less than 50 microns sand were not able to be tested on the separator due to various problems. The graph below shows that separation efficiency increases with particle size which matches our conclusion.

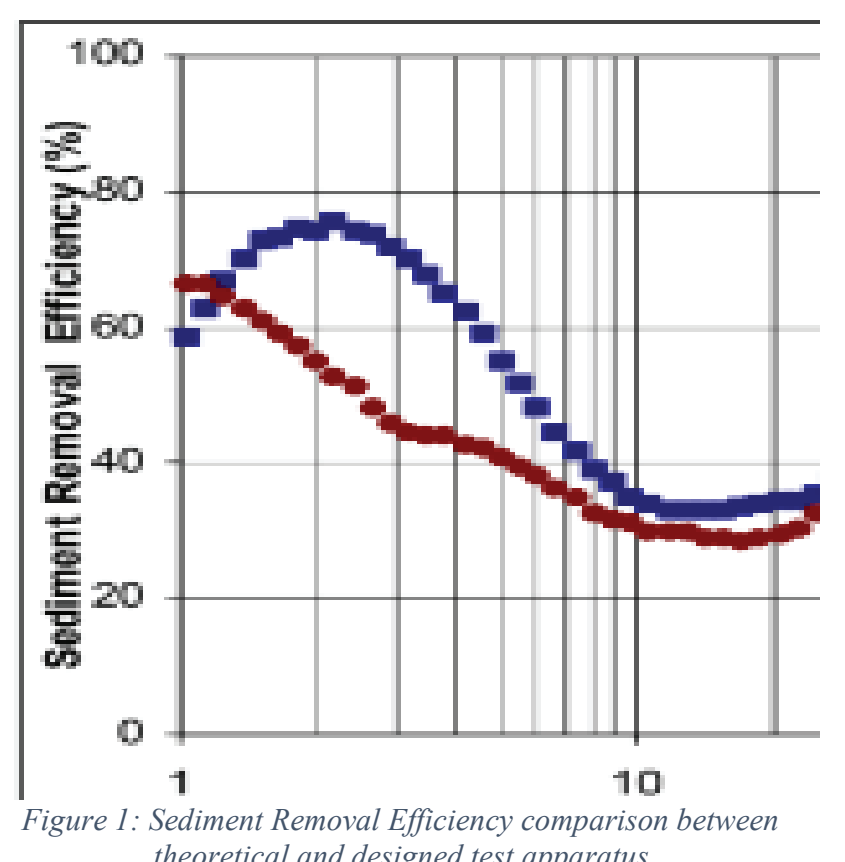
theoretical and designed test apparatus

\section{CONCLUSION}

The hydrocyclone is capable of separating particles upto $48 \mu \mathrm{m}$ critical diameter at flow rate 1 lit/sec with $70 \%$ separation efficiency. The efficiency 
is affected by the dimensional errors. Increasing the dimensional accuracy will increase the separation efficiency. This device is aimed to replace the settling tanks in hydropower plants to minimize head loss and increase the separation efficiency.

\section{ACKNOWLEDGEMENT}

This project was possible due to the supervision and information provided to us by our supervisors Er.Aman Kapali and Er. Rabin Dhakal. So we are thankful to them for providing support and we also like to acknowledge Turbine Testing lab (TTL) for support.

\section{References}

[1] Dhakal, Sagar, et al. "Comparison of cylindrical and conical basins with optimum position of runner: Gravitational water vortex power plant." Renewable and Sustainable Energy Reviews 48 ( 2015): 662-669.

[2] Dhakal , R., et al. "Technical and economic prospects for the site implementation of a gravitational water vortex power plant in Nepal." 2016 IEEE International Conference on Renewable Energy Research and Applications ( ICRERA). IEEE, 2016.

[3] Dhakal, Rabin, et al. "Inlet and Outlet Geometrical Condition for Optimal Installation of Gravitational Water Vortex Power Plant with Conical Basin Structure ." Recent Advances in Mechanical Infrastructure. Springer, Singapore, 2020. 163-174
[4] Dhakal , Sagar , et al. "Effect of dominant parameters for conical basin: Gravitational water vortex power plant." Proceedings of IOE graduate conference. 2014

[5] B. Thapa, "Sand Erosion in Hydraulic Machinery," March 2010. [Online]. Available: Fakultet for in geniørvitenskap ogteknologi online. [Accessed 0907 2019].

[6] H. Neopane, "Sediment Erosion in Hydro Turbines," March 2010. [Online]. [Accessed October 2018].

[7] G. D. A. G. PRAVEEN, "Study on design and performance evaluation of hydrocyclone seperator for micro irrigation system," International Journal of Agricultural Engineering, vol. 4, no. 2, pp. 200205, October 2011.

[8] G. D. A. G. PRAVEEN, "Study on design and performance evaluation of hydrocyclone separators for micro-irrigation system," July 2011. [Online]. [Accessed Dec 2018].

[9] Dhakal, Rabin, et al. "Economic feasibility study of gravitational water vortex power plant for the rural electrification of low head region of nepal and its comparative study with other low head power plant." Conference proceeding of the 11th international conference on ASEAN knowledge networks for the economy, society, culture, and environmental stability, Kathmandu. 2015. 